\title{
Grain Boundary Chemistry and Transport Through Alumina Scales on NiAl Alloys
}

\author{
Torben Boll ${ }^{1}$ (D) Kinga A. Unocic ${ }^{2}$ - Bruce A. Pint ${ }^{2}$ •

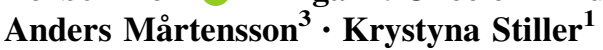

Received: 1 December 2016/Published online: 12 January 2017

(C) The Author(s) 2017. This article is published with open access at Springerlink.com

\begin{abstract}
It is widely accepted that the growth of protective $\alpha-\mathrm{Al}_{2} \mathrm{O}_{3}$ scales on $\mathrm{Ni}$ based alloys is governed by the inward diffusion of oxygen through the oxide grain boundaries (GB). However, there is also some outward diffusion of metal ions to the surface, but it is difficult to quantify. In this work we apply atomic force microscopy, scanning electron microscopy and transmission electron microscopy to investigate the outward flux of $\mathrm{Al}$, which manifests as the growth of small ridges along the alumina GBs after the removal of the outermost oxide layer by mechanical polishing or focused ion beam techniques followed by additional oxidation. As a model alumina-former, $\mathrm{NiAl}$ with $\mathrm{Hf}$ and $\mathrm{Zr}$ additions was investigated. In comparison to $\mathrm{Zr}$, Hf was found to reduce the outward $\mathrm{Al}$ diffusion. This outward diffusion was six orders of magnitude smaller than the $\mathrm{O}$ inward diffusion.
\end{abstract}

Keywords Oxidation - Diffusion - Grain boundaries · Reactive elements · Atom probe tomography

\section{Introduction}

Alumina is important as a structural material, as well as a functional material in electronics and as a thermally grown external oxide or scale on Al-containing hightemperature alloys. For the past 25 years, it has been generally recognized that transport through a growing $\alpha-\mathrm{Al}_{2} \mathrm{O}_{3}$ scale takes place predominantly by the inward

Torben Boll

torbenb@chalmers.se

1 Department of Physics, Chalmers University of Technology, 41296 Göteborg, Sweden

2 Materials Science and Technology Division, Oak Ridge National Laboratory, Oak Ridge, TN 37831, USA

3 Department of Applied Chemistry, Chalmers University of Technology, 41296 Göteborg, Sweden 
diffusion of $\mathrm{O}$ along grain boundaries when a reactive element (RE) is present [1-11]. Without a RE addition, a mixed $\mathrm{Al}$ and $\mathrm{O}$ growth was observed for $\alpha-\mathrm{Al}_{2} \mathrm{O}_{3}$. Some prior growth mechanism studies were confounded by the formation of cubic alumina phases such as $\theta-\mathrm{Al}_{2} \mathrm{O}_{3}$ [7], which grow by outward transport [12]. Recent studies have noted that some concurrent outward $\mathrm{Al}$ diffusion along grain boundaries does occur in RE-doped $\alpha-\mathrm{Al}_{2} \mathrm{O}_{3}$ [13-15]. While $\mathrm{O}$ transport is readily studied by ${ }^{18} \mathrm{O}$ tracers, it is much more difficult to study $\mathrm{Al}$ transport. There is only one stable isotope, and its radioactive isotope, $\mathrm{Al}^{26}$, has a lifetime of only about $25 \mathrm{~h}$. The diffusivity of $\mathrm{Al}^{26}$ in alumina was investigated by Fielitz et al. [16]. However, in order to study outward diffusion, the isotope must be in the alloy or in the oxide beneath a previously formed oxide.

There is still some debate about the exact mechanism by which alloy additions like REs affect diffusional fluxes [6]. It is well known that alloy chemistry can dramatically affect the scale performance, including RE additions and S [17-21]. However, most explanations for such observations are only qualitative. Ideally, the most protective, slow-growing scale will contain large $\alpha$-alumina grains adjacent to the metal, i.e., one with few grain boundaries where transport occurs. In many cases, on top of these large columnar grains, smaller grains also are present. For $\mathrm{NiAl}$, these grains result from the transformation of cubic $\mathrm{Al}_{2} \mathrm{O}_{3}$ phases $(\gamma$ - and/or $\theta$ ), which form during the initial exposure. Due to the difference between the stable and transient alumina lattice parameters, a layer containing voids is formed between the two regions [2, 6, 22-25].

This study describes the initial work aimed at improving the understanding of transport processes in alumina by conducting well-controlled oxidation exposures and applying high-resolution microscopy techniques for characterization of grain boundary chemistry. Two NiAl alloys were studied with different RE additions. Similar to prior studies $[13,14]$, the outward transport was studied by removing the outermost part of the scale, created during a longer exposure, and re-oxidizing the samples for a short time. Several different strategies were used that avoid the issue of loss of constraint in the scale, which was an issue in the prior work. Characterization of the regrown scale combined with modeling was used to quantify the very low level of outward transport observed in this study.

\section{Experimental Procedures}

\section{Basic Idea}

To calculate the outward flux $J_{\mathrm{Al}}$ of aluminum atoms along GBs, an earlier study [14] relied on AFM of ridges on top of GBs of an outward growing oxide. Because the oxidation process produced small grains and voids (Fig. 1a) in the outer oxide and a rough topography (Fig. 2a), observation of ridges was difficult and it was necessary to remove this layer. The three-step process presented in Fig. 1 was applied: (a) formation of a protective oxide in the 1st exposure, (b) removal of the outer layer with small grains and voids, with concomitant smoothing of the surface, and (c) a 2nd exposure followed by measuring ridge formation. Due to the strong 
(a) After $1^{\text {st }}$ exposure
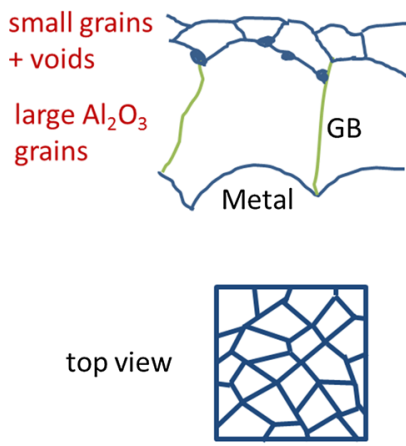

(b) Polishing/ Milling
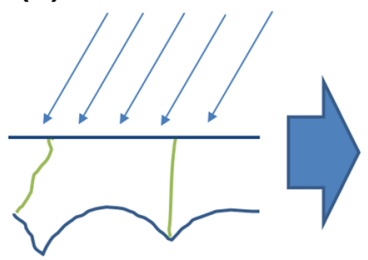

(c) $2^{\text {nd }}$ Exposure

outward growing oxide
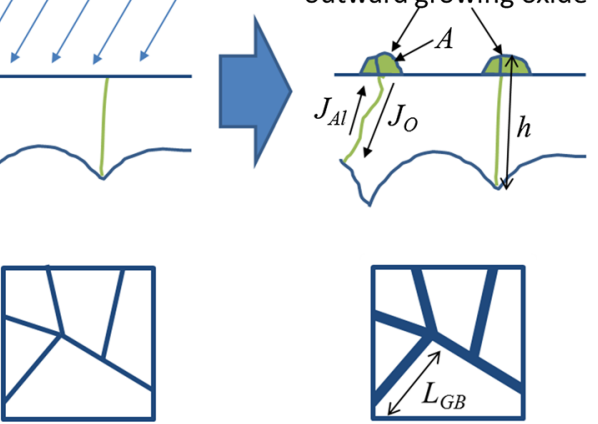

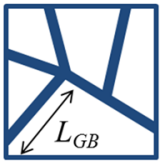

Fig. 1 Sketch of the principle. a The GBs and PBs after the 1st exposure, $\mathbf{b}$ after the removal of the small grains and $\mathbf{c}$ after the 2 nd exposure as side and top view

(a)
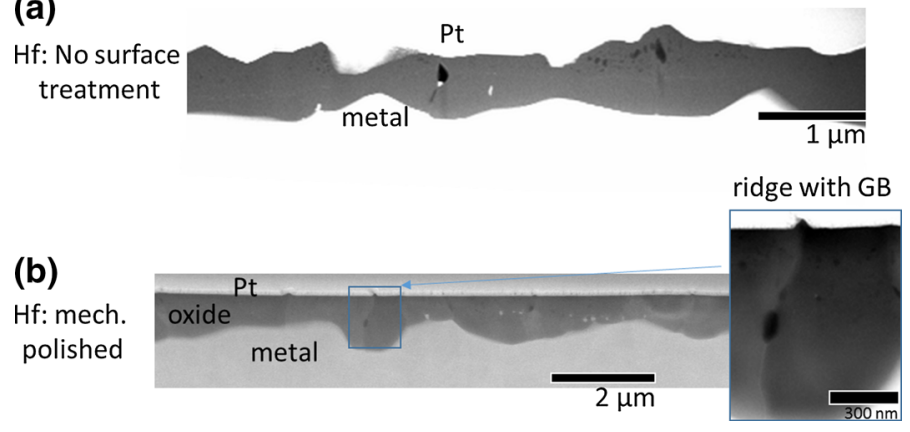

Fig. 2 HAADF-STEM image of the cross-section of Hf-doped NiAl after 2nd exposure a without surface treatment and $\mathbf{b}$ with mechanical polishing

local variations of the oxide thickness (Fig. 2b), we have to perform a very local analysis using cross-section TEM. The top view in Fig. 1 shows that removing the oxide results in a much easier to interpret topography due to the large grain size. The general idea then is to calculate the flux from the volume of outward diffused material on top of a GB.

For an infinitesimal small time $\Delta t$, the flux through a GB with lateral length $L_{\mathrm{GB}}$ can be defined from the number $N_{\mathrm{GB}}^{\mathrm{Al}}$ of transported atoms as $J_{A l}=N_{\mathrm{GB}}^{\mathrm{Al}} /\left(L_{\mathrm{GB}} \Delta t\right)$. Since the volume $V_{\mathrm{u}}=2.54 \times 10^{-22} \mathrm{~cm}^{3}$ of the $\mathrm{Al}_{2} \mathrm{O}_{3}$ unit cell, which contains 12 $\mathrm{Al}$ atoms, is known and the volume $V$ of the ridge is $V=N_{\mathrm{GB}}^{\mathrm{Al}} V_{\mathrm{u}} / 12$, and the flux can be calculated directly from the cross-sectional area $A$ of the ridge as $J_{\mathrm{Al}}=12 A / V_{\mathrm{u}}$, where $A$ was obtained from the height and width of the resulting triangle. The obtained flux will depend on the vertical length of the GB, which we consider as the oxide thickness $h$ of the oxide, which is the direct line between the grain boundary exit at the metal to and the upper end of the ridge (Fig. 1c). 


\section{Materials and Methods}

Two different $\mathrm{NiAl}$ alloys with additions of $\mathrm{Hf}$ and $\mathrm{Zr}$ were studied. Their composition (Table 1) was determined by inductively coupled plasma atomic emission spectroscopy (ICP-AES) and combustion analyses. The materials were subjected to an initial exposure in $\mathrm{O}_{2}$ at $1100{ }^{\circ} \mathrm{C}$ for $100 \mathrm{~h}$. After this treatment, called 1st exposure in the following text, the outermost oxide layer was removed using focused ion beam milling or mechanical polishing. The samples were then reexposed to $\mathrm{O}_{2}$ at $1100{ }^{\circ} \mathrm{C}$ for $10 \mathrm{~h}$, which is referred to as the 2 nd exposure.

For the mechanical polishing, P2400 polishing paper was used, followed by diamond spray with decreasing grain sizes of $15,3,1$, and $0.25 \mu \mathrm{m}$. The polishing was performed at a small angle to the surface by applying more pressure to one side of the sample. For the ion beam preparation, a plasma-focused ion beam (FIB) from Tescan (Xe-FIB) and a Versa 3D (Ga-FIB) from FEI were used to ion mill circleshaped patterns into the oxide with depths between 0.3 and $2 \mu \mathrm{m}$. Table 2 presents the investigated conditions of the two alloys. Scanning electron microscopy (SEM) characterization and high-angle annular dark-field scanning transmission electron microscopy (HAADF-STEM) lamella production also were performed in the Versa 3D. For STEM and energy dispersive spectroscopy (EDS) mapping, a FEI Titan or Tecnai was used. For atomic force microscopy (AFM), a Digital Instruments Nanoscope IIIa was used.

\section{Results}

\section{Scanning Electron Microscopy and Atomic Force Microscopy}

The specimens showed the expected [2] outer region consisting of relatively small alumina grains with some $\mathrm{Zr}$ or Hf oxide precipitates and voids. Underneath is a layer with larger $\mathrm{Al}_{2} \mathrm{O}_{3}$-oxide grains. Because of the initial surface roughness (Fig. 2a), the removal of the oxide was not homogeneous, and the position on the sample could only be qualitatively related to the remaining oxide's thickness. After ion milling, an overview of the sample surface was made by SEM and suitable areas for further studies by either AFM or STEM after the 2nd exposure was identified. Backscattered electron (BSE) imaging enabled the observation of GB RE

Table 1 Compositions of alloys as determined by ICP-AES

\begin{tabular}{ccccccccccc}
\hline Material & $\begin{array}{l}\mathrm{Ni} \\
\text { at.\% }\end{array}$ & $\begin{array}{l}\mathrm{Al} \\
\text { at.\% }\end{array}$ & $\begin{array}{l}\mathrm{Zr} \\
\mathrm{ppma}\end{array}$ & $\begin{array}{l}\mathrm{Hf} \\
\mathrm{ppma}\end{array}$ & $\begin{array}{l}\mathrm{N} \\
\mathrm{ppma}\end{array}$ & $\begin{array}{l}\mathrm{C} \\
\mathrm{ppma}\end{array}$ & $\begin{array}{l}\mathrm{S} \\
\mathrm{ppma}\end{array}$ & $\begin{array}{l}\mathrm{O} \\
\mathrm{ppma}\end{array}$ & $\begin{array}{l}\mathrm{B} \\
\mathrm{ppma}\end{array}$ & $\begin{array}{l}\mathrm{Cr} \\
\mathrm{ppma}\end{array}$ \\
\hline $\begin{array}{c}\mathrm{Zr}- \\
\text { doped }\end{array}$ & 49.95 & 49.99 & 520 & 0 & 0 & 0 & 3 & 48 & 30 & 0 \\
$\begin{array}{c}\text { Hf- } \\
\text { doped }\end{array}$ & 49.83 & 50.07 & 0 & 480 & 30 & 36 & $<3$ & 43 & 0 & 100 \\
\hline
\end{tabular}


Table 2 The performed analyses on the Hf- and Zr-doped NiAl before and after the 2nd exposure

\begin{tabular}{lccccc}
\hline Surface treatment & AFM before & AFM after & SEM & STEM after & EDS after \\
\hline Hf & & & & & \\
No surface treatment & & & $X$ & $X$ & $X$ \\
Ga-FIB milling & $\mathrm{X}$ & $\mathrm{X}$ & $\mathrm{X}$ & & \\
Xe-FIB milling & $\mathrm{X}$ & $\mathrm{X}$ & $\mathrm{X}$ & $\mathrm{X}$ & $\mathrm{X}$ \\
Mech. Polishing & & $\mathrm{X}$ & $\mathrm{X}$ & $\mathrm{X}$ & $\mathrm{X}$ \\
Zr & & & & & \\
No surface treatment & & $\mathrm{X}$ & & \\
Ga-FIB milling & $\mathrm{X}$ & $\mathrm{X}$ & $\mathrm{X}$ & $\mathrm{X}$ & $\mathrm{X}$ \\
Xe-FIB milling & $\mathrm{X}$ & $\mathrm{X}$ & $\mathrm{X}$ & & \\
Mech. polishing & & $\mathrm{X}$ & $\mathrm{X}$ & $\mathrm{X}$ & $\mathrm{X}$ \\
\hline
\end{tabular}

enrichment (Fig. 3a). The bright areas in this figure are regions of exposed metal strongly oxidized after the 2nd exposure (Fig. 3b). Bright areas after the 2nd exposure are most likely Hf-rich precipitates below the oxide. After the 2nd exposure, the GBs were much more prominent, indicating that ridge growth occurred. This behavior was observed for all preparation methods (mechanical polishing, Xe-FIB and Ga-FIB) and both dopants.

Height profiles were obtained by AFM. Before the 2nd exposure, surface roughness (Fig. 4a, d) partially correlated with GB positions, especially for the Gamilled samples. This made it harder to observe the ridge growth (Fig. 4b, e). This suggested that the higher ion mass of Xe plus defocusing of the beam [attained by the Tescan (Xe-FIB)] helped to produce smoother surfaces. This can be further complicated close to areas where the metal was visible before the 2nd exposure, since the oxide grew more quickly there during re-oxidation. For all of the samples, ridge growth was observed. For the mechanical polished samples, well-defined ridges were observed due to a very smooth initial surface (Fig. 4c, f). On the other

(a) Before $2^{\text {nd }}$ exposure

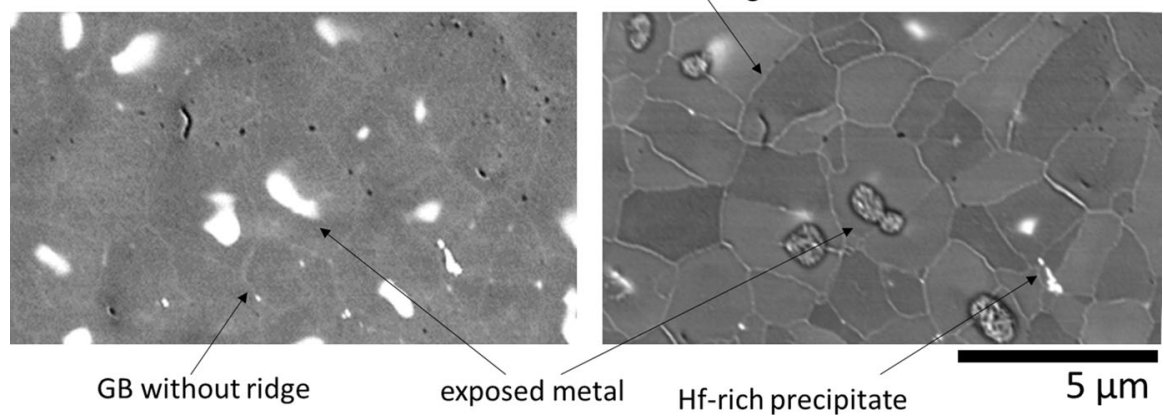

Fig. 3 SEM BSE images of a Xe-FIB Hf-doped NiAl $\mathbf{a}$ before and $\mathbf{b}$ after exposure at the same position 

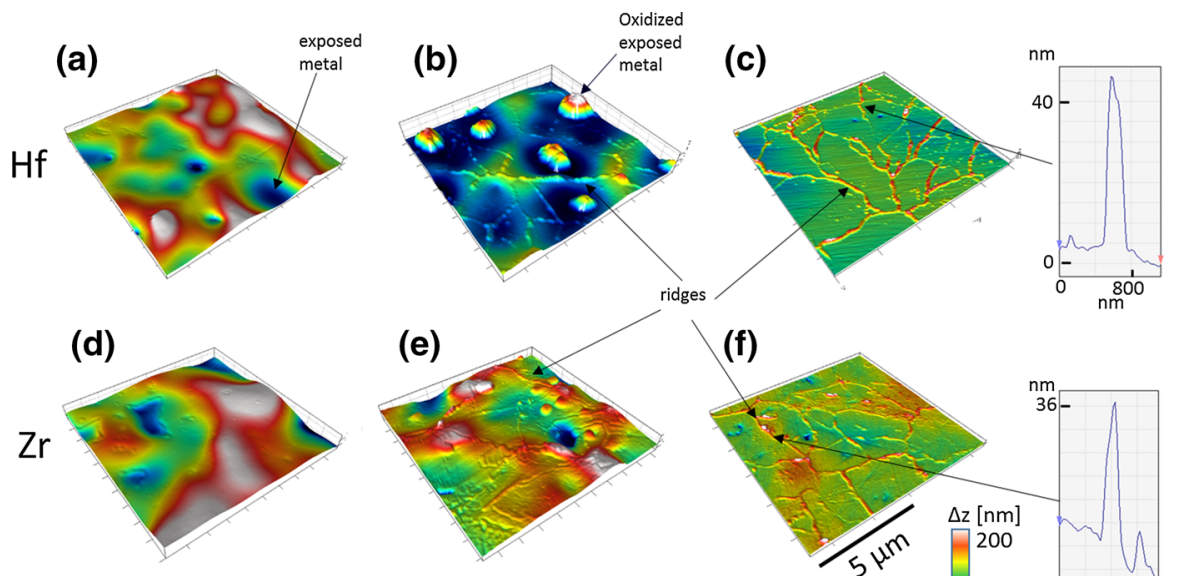

Xe-FIB

unexposed

Xe-FIB exposed

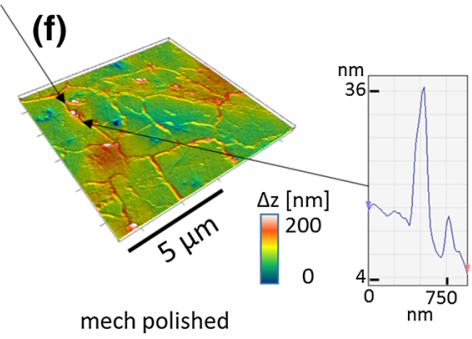

exposed

Fig. 4 AFM of the FIB-milled and mechanically polished surfaces before (a, d) and after (b, c, e, f) the 2nd exposure: the area dimensions are $10 \mu \mathrm{m} \times 10 \mu \mathrm{m}$. The height of surface roughness is exaggerated by a factor 2 (Color figure online)

hand, it was not possible to find a quantitative difference among the different samples using AFM alone since the ridge height (typically in the range of $50 \mathrm{~nm}$ ) was dependent on the thickness of the underlying oxide. AFM does not allow determination of the local oxide thickness so a quantitative analysis of GB transport could not be performed.

\section{Transmission Electron Microscopy}

Before the 2nd exposure, the average oxide thickness was $\sim 1 \mu \mathrm{m}$ (Fig. 2b), but the exposed metal suggested considerable variation in that thickness. In our RE-doped $\mathrm{NiAl}$ samples (Fig. 2), the exposed grain sizes were several $\mu$ m laterally, exceeding the thickness of the oxide scale. In Fig. 2b, the HAADF-STEM image indicated ridge growth on top of the GBs (inset in Fig. 2b) as a result from the 2nd exposure Ridges that overlapped where two GBs were very close were ignored. The variation in oxide thickness carried over to all milled and mechanical polished samples. In the case of the ion milled samples, the rough surface topography was maintained. The height and width of the ridges depended on the underlying grain boundary height, $h$, such that as $h$ increased the ridge dimensions were reduced. In contrast, the ridge growth was larger for low $\mathrm{h}$ values as displayed in Fig. 5 for Xe-milled Hf-doped $\mathrm{NiAl}$. Figure 6 shows mechanically polished $\mathrm{Zr}$-doped $\mathrm{NiAl}$ where the ridge crosssection resembles a half sphere or a triangle where the oxide was thick. For both Hfand $\mathrm{Zr}$-doped NiAl, EDS elemental maps revealed that GBs were RE enriched (Figs. 5b, 6b). For Zr-doped NiAl, a $\mathrm{Zr}$ enrichment at the metal-oxide interface also was observed. For the Ga-milled samples, we could observe the formation of a Ga 
(a)

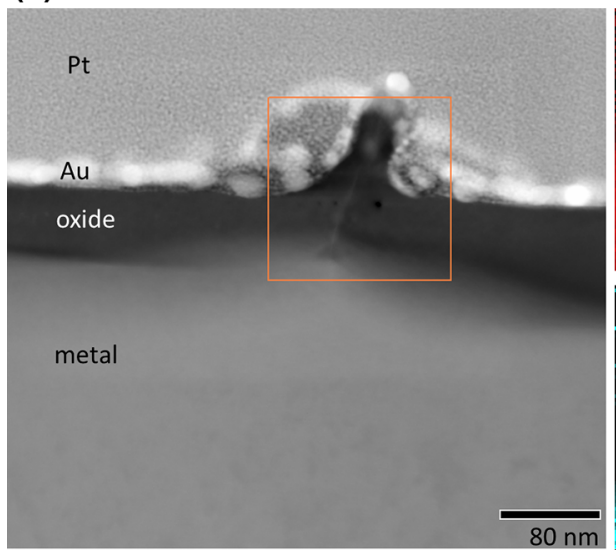

(b)

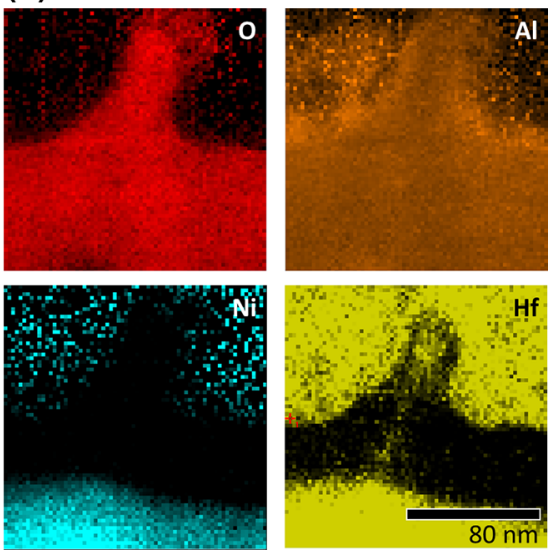

Fig. 5 a HAADF-STEM image of a ridge on a Xe-milled after 2nd exposure, b EDS maps showing Hf enrichment extending through the ridge. Pt, which covers the ridge, is wrongly identified as $\mathrm{Hf}$ in this image

(a)

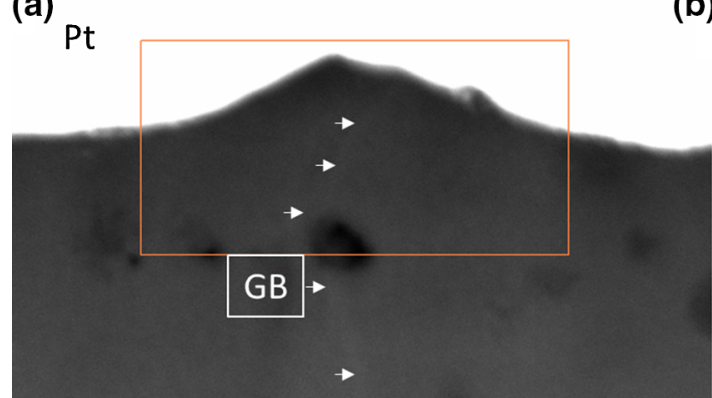

oxide (b)

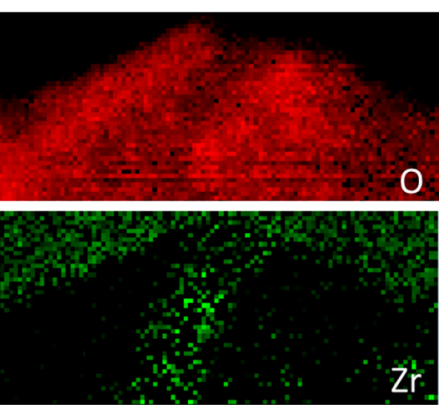

$2 \mathrm{r}$

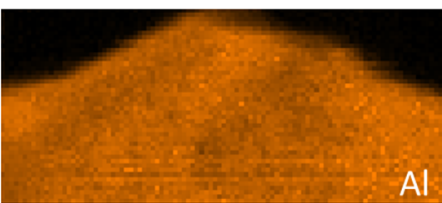

Fig. 6 a HAADF-STEM image of the mechanically polished Zr-doped NiAl sample after the 2nd exposure. b EDS elemental maps, enrichment of $\mathrm{Zr}$ at the GB is clearly visible

and $\mathrm{Ni}$ containing aluminum oxide, which seemed to grow from the surface into the oxide.

\section{Al Transport Calculations}

Using the procedure described above in the general concept section, the Al transport results for the different samples are displayed in Fig. 7 using a double-logarithmic plot of the flux $J$ of Al against the thickness of the oxide, $h$. The Xe-FIB prepared Hf-doped NiAl sample followed Fick's 1st law as indicated by the plotted line. The 


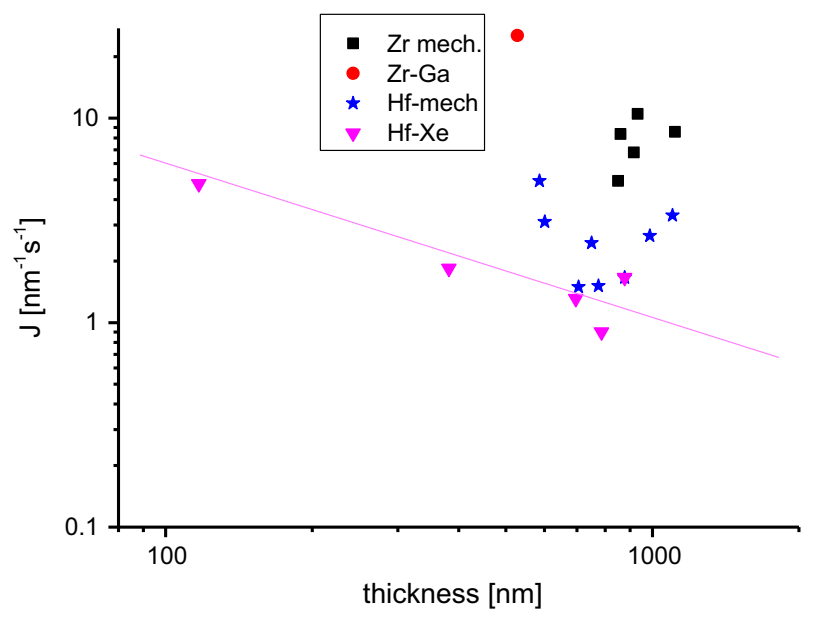

Fig. 7 The outward flux $J$ in dependence of the oxide thickness as measured from TEM images

mechanical polished Hf-doped sample appeared to display a higher Al flux than was observed for Xe-milling.

\section{Discussion}

To remove the outer oxide, three different methods were used in this study to investigate the role of sample preparation: (a) mechanical polishing, (b) milling using $\mathrm{Ga}$ and (c) milling using Xe-ions. AFM studies of the re-exposed samples showed the formation of oxide ridges above oxide GBs in all cases. However, the non-uniform oxide allowed only a qualitative observation of the outward diffusion in comparison to Nychka et al. [14] and Yang et al. [15]. But yet, Nychka and Tolpygo used only a tapered sectioning technique, i.e., mechanical polishing. The problem with this technique is that there is a loss of constraint of the in-plane stresses in the scale. If this stress is important in affecting transport, as argued by Clarke [26], then the results from this method may not be valid. Nychka et al. found that MA956, an oxide dispersion strengthened FeCrAl alloy, had the least outward transport. This alloy also had the highest strength at temperature and would be least likely to deform under the stress state created by the polishing. Thus, the comparison with Ga and Xe milling in this study attempted to address that issue.

The mechanical polished Hf-doped sample generally seems to display a higher flux than the Xe-milled one, which could be caused by the chemically inert Xe ions remaining on the oxide GB in small quantities, not detectable by STEM-EDS, and acting as an additional obstacle to any diffusion. As another, more likely, explanation is that the strong mechanical deformation during the polishing could have induced additional dislocations, enabling faster diffusion for such samples. Comparing mechanical polished samples, the flux for the Zr-doped NiAl sample was about 5-10 times higher than for the Hf-doped NiAl sample. Generally, all 
observed fluxes were in the range of several atoms/(nm s), which seems to correlate well with the results of Nychka et al. [14] for Al outward diffusion through alumina on an $\mathrm{Fe}-\mathrm{Cr}-\mathrm{Al}$ alloy. In Nychka's work, for a similar oxide thickness, fluxes were in the range of 1-100 atoms/(nm s) depending on the alloy composition.

A large variation in the outward flux, $J$, was observed. Errors in measurements of the ridge dimensions are not likely the largest source of error, accounting for $<20 \%$ for the worst cases. (However, all measurements were obtained from cross-sections, which cannot capture the 3-dimensional ridge growth.) Of more importance are differences in morphologies of the investigated GBs. In several cases, the investigated GBs contained second phase precipitates or voids, which influenced diffusion and the accuracy of the GB height measurement. Another important issue is the difference between high- and low-angle GBs, which is known to have an impact on segregation $[25,27]$. All these factors appear to contribute to the observed scatter of the calculated flux.

To understand the relevance of the outward flux $J_{\mathrm{Al}}$ of $\mathrm{Al}$ for the oxidation process, it is necessary to compare it to the inward flux $J_{\mathrm{O}}$ of $\mathrm{O}$ into the metal. An approximate value for $J_{\mathrm{O}}$ in dependence of the oxide thickness can be obtained from the mass gain curves. The thickness $h$ of the oxide at every time of the oxidation is obtained by a measurement of the average thickness of the oxide in STEM images after the exposures, which is $0.9 \mu \mathrm{m}$ (Fig. 2a), and assuming the initial thickness is zero. The development of the thickness between these two values is estimated to follow the mass gain curve. For thick scales, it can be assumed that the outward growth is negligible and that all oxygen is converted to $\alpha-\mathrm{Al}_{2} \mathrm{O}_{3}$.

The flux through a 2-dimensional surface $S i$ s $-\frac{\mathrm{d}}{\mathrm{d} t} N_{\mathrm{O} \text {,tot }}(t) / S$. With the weight of one $\mathrm{Al}$ atom $m_{\mathrm{O}}=16 \mathrm{Da}=26.6 \times 10^{-27} \mathrm{~kg}$ and the total number of reacted $\mathrm{O}$ atoms $N_{\mathrm{O} \text {,tot }}=m_{\mathrm{tot}} / m_{\mathrm{O}}$ depends on the gained mass $m_{\mathrm{tot}}$ and thus the gained volume. To calculate the flux through the 1-dimensional GBs, it is necessary to know the grain boundary density $v$. This density can be obtained from SEM images (Fig. 3b) by counting the number of GBs that intersect with randomly drawn lines. Additionally, we assume that the GBs form a grid with square meshes of equal size. For the Hf-doped NiAl alloy, $v=1.26 \cdot(14) \times 10^{-4} \mathrm{~nm}^{-2}$. The inward GB flux is thus $J_{\mathrm{O}}=-\frac{\mathrm{d}}{\mathrm{d} t} N_{\mathrm{O} \text {,tot }}(t) /\left(S_{\mathrm{tot}} v\right)$ with the sample surface area $S_{\mathrm{tot}}$. Apart from the already mentioned approximations, this calculation also relies on the growth being homogeneous with uniform thickness, which is not the case as observed in TEM (Fig. 2a). The resulting values for $J_{\mathrm{O}}$ for the mechanical polished Hf-doped NiAl sample are in the range of $10^{6} \mathrm{~s}^{-1} \mathrm{~nm}^{-1}$, which is six orders of magnitude larger than for the outward diffusion of Al. Thus, if $\mathrm{Zr}$-doped NiAl is $10 \mathrm{X}$ higher, the outward transport still represents a tiny fraction of the total growth. Future work is planned to study undoped alumina formed on binary $\mathrm{NiAl}$ for comparison as well as RE-doped NiCrAl. Until present, we only investigated the influence of two dopants. To be able to judge the relevance of the outward growth for this type of alloys, we are planning to investigate both binary $\mathrm{NiAl}$ with no dopants and ternary $\mathrm{Ni}-\mathrm{Cr}-\mathrm{Al}$ alloys with additions of $\mathrm{Y}$ and Hf. Furthermore, since the quantification of faint segregation to the GB by TEM techniques is difficult, if not impossible, we are conducting at present atom probe tomography studies of GB and ridges. 


\section{Conclusions}

Oxide ridges were observed to grow on Hf- and $\mathrm{Zr}$-doped NiAl during a second oxidation period at $1100{ }^{\circ} \mathrm{C}$ after removal of the outermost oxide layer for all the removal methods: ion milling with $\mathrm{Ga}$ or Xe and mechanical polishing. This confirms previous studies that some outward grain boundary transport of $\mathrm{Al}$ occurs during the growth of alumina doped with a reactive element (i.e., $\mathrm{Hf}$ or $\mathrm{Zr}$ ). However, the measured outward flux of Al was 5-6 orders of magnitude smaller than the flux for the inward diffusion of $\mathrm{O}$, which was in the range of $10^{6} \mathrm{~s}^{-1} \mathrm{~nm}^{-1}$. Thus, the contribution of the outward $\mathrm{Al}$ flux had negligible effect on the mass gain or the oxide thickness on doped NiAl. In this study, the oxide thickness was not uniform. However, using HAADF-STEM images, it was still possible to study the outward transport. An influence of the dopant on the outward flux was found: replacing $\mathrm{Zr}$ with $\mathrm{Hf}$ reduced the outward flux by a factor of 5-10 in NiAl.

Acknowledgements The authors would like to thank Patrik Alnegren and Kristina Hellström from Chalmers for help with the oxidations exposures and Tracie Lowe, Adam W. Willoughby, Michael S. Stephens from ORNL for assistance with experimental work. This research is supported by Swedish Energy Agency.

Open Access This article is distributed under the terms of the Creative Commons Attribution 4.0 International License (http://creativecommons.org/licenses/by/4.0/), which permits unrestricted use, distribution, and reproduction in any medium, provided you give appropriate credit to the original author(s) and the source, provide a link to the Creative Commons license, and indicate if changes were made.

\section{References}

1. K. P. R. Reddy, J. L. Smialek and A. R. Cooper, Oxidation of Metals 17, 429 (1982).

2. R. Prescott, D. F. Mitchell, M. J. Graham and J. Doychak, Corrosion Science 37, 1341 (1995) .

3. W. J. Quadakkers, A. Elschner, W. Speier and H. Nickel, Applied Surface Science 52, 271 (1991). doi:10.1016/0169-4332(91)90069-V.

4. B. A. Pint, J. R. Martin and L. W. Hobbs, Oxidation of metals 39, 167 (1993).

5. J. Jedlinski, J. L. Grosseau Poussard, G. Smoła, et al., Materials at High Temperatures 29, 59 (2012). doi:10.3184/096034012X13349146318471.

6. A. H. Heuer, D. B. Hovis, J. L. Smialek and B. Gleeson, Journal of the American Ceramic Society 94 , s146 (2011). doi:10.1111/j.1551-2916.2011.04573.x.

7. G. C. Rybicki and J. L. Smialek, Oxidation of Metals 31, 275 (1989). doi:10.1007/BF00846690.

8. E. W. A. Young and J. H. W. de Wit, Oxidation of Metals 26, 351 (1986). doi:10.1007/BF00659341.

9. W. J. Quadakkers, H. Holzbrecher, K. G. Briefs and H. Beske, Oxidation of Metals 32, 67 (1989). doi:10.1007/BF00665269.

10. E. Schumann, J. C. Yang, M. Rühle and M. J. Graham, Oxidation of Metals 46, 37 (1996). doi:10. 1007/BF01046883.

11. C. Mennicke, E. Schumann, M. Rühle, et al., Oxidation of Metal 49, 455 (1998). doi:10.1023/A: 1018803113093.

12. B. A. Pint, J. R. Martin and L. W. Hobbs, Solid State Ionics 78, 99 (1995). doi:10.1016/01672738(95)00013-V.

13. V. K. Tolpygo and D. R. Clarke, Materials at High Temperatures 20, 261 (2003). doi:10.3184/ 096034003782748892.

14. J. A. Nychka and D. R. Clarke, Oxidation of Metals 63, 325 (2005). doi:10.1007/s11085-005-4391-4. 
15. H. J. Yang, Y. T. Pei and J. T. M. De Hosson, Scripta Materialia 69, 203 (2013). doi:10.1016/j. scriptamat.2013.04.013.

16. P. Fielitz, G. Borchardt, S. Ganschow, et al., Solid State Ionics 179, 373 (2008). doi:10.1016/j.ssi. 2008.03.007.

17. J. L. Smialek, D. T. Jayne, J. C. Schaeffer and W. H. Murphy, Thin Solid Films 253, 285 (1994). doi:10.1016/0040-6090(94)90335-2.

18. B. A. Pint, Oxidation of Metals 45, 1 (1996). doi:10.1007/BF01046818.

19. P. Y. Hou, Journal of the American Ceramic Society 86, 660 (2003). doi:10.1111/j.1151-2916.2003. tb03355.x.

20. T. Nakagawa, I. Sakaguchi, N. Shibata, et al., Acta Materialia 55, 6627 (2007). doi:10.1016/j. actamat.2007.08.016.

21. D. Naumenko, B. A. Pint and W. J. Quadakkers, Oxidation of Metals 86, 1 (2016). doi:10.1007/ s11085-016-9625-0.

22. B. A. Pint, K. L. More, I. G. Wright and P. F. Tortorelli, Materials at High Temperatures 17, 165 (2000). doi:10.1179/mht.2000.024.

23. B. A. Pint, K. L. More and I. G. Wright, Materials at High Temperatures 20, 375 (2003). doi:10. 1179/mht.2003.044.

24. B. A. Pint, K. L. More and I. G. Wright, Oxidation of Metals 59, 257 (2003). doi:10.1023/A: 1023087926788.

25. B. A. Pint and K. L. More, Journal of Materials Science 44, 1676 (2009). doi:10.1007/s10853-0083221-x.

26. D. R. Clarke, Acta Materialia 51, 1393 (2003). doi:10.1016/S1359-6454(02)00532-3.

27. D. Raabe, M. Herbig, S. Sandlöbes, et al., Current Opinion in Solid State and Materials Science 18, 253 (2014). doi:10.1016/j.cossms.2014.06.002. 